\title{
AFRL-RW-EG-TR-2014-121
}

\section{MESOSCALE MODELING OF ENERGETIC MATERIALS}

\section{Michael E Nixon and Martin J. Schmidt}

\author{
AFRL/RWML
}

OCT 2014

\section{INTERIM REPORT}

DISTRIBUTION A. Approved for public release; distribution is unlimited; 96ABW-2012-0263.

\section{AIR FORCE RESEARCH LABORATORY MUNITIONS DIRECTORATE}




\section{NOTICE AND SIGNATURE PAGE}

Using Government drawings, specifications, or other data included in this document for any purpose other than Government procurement does not in any way obligate the U.S. Government. The fact that the Government formulated or supplied the drawings, specifications, or other data does not license the holder or any other person or corporation; or convey any rights or permission to manufacture, use, or sell any patented invention that may relate to them.

Qualified requestors may obtain copies of this report from the Defense Technical Information Center (DTIC) <http://www.dtic.mil/dtic/index.html>.

AFRL-RW-EG-TR- 2014-121 HAS BEEN REVIEWED AND IS APPROVED FOR
PUBLICATION IN ACCORDANCE WITH ASSIGNED DISTRIBUTION STATEMENT.

FOR THE DIRECTOR:

Digitally signed by EWING.CRAIG.M.1229434825

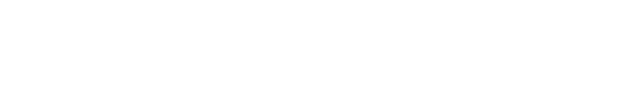
Date: 2014.12 .10 08:28:36 -06'00'

CRAIG EWING, DR-IV, PhD.

CTC Lead, Munitions Effects Sciences

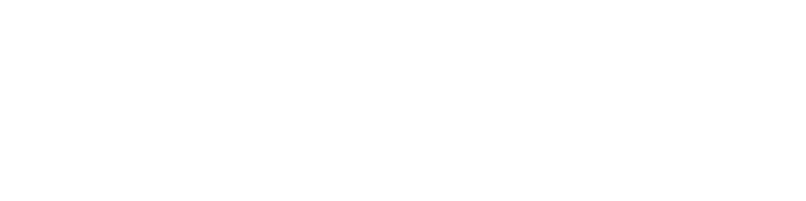

MARTIN J. SCHMIDT, DR-III, PhD.

Work Unit Manager

This report is published in the interest of scientific and technical information exchange, and its publication does not constitute the Government's approval or disapproval of its ideas or findings. 


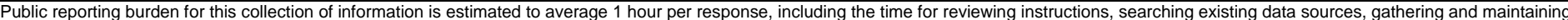

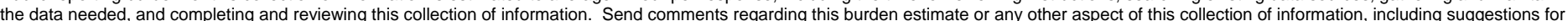

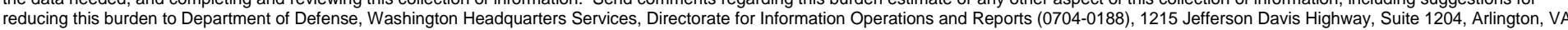

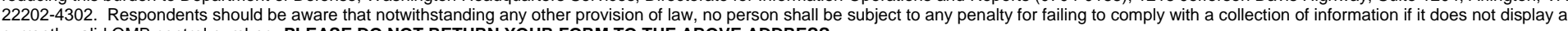
currently valid OMB control number. PLEASE DO NOT RETURN YOUR FORM TO THE ABOVE ADDRESS.

\begin{tabular}{|l|l|c|}
\hline 1. REPORT DATE 10-23-2014 & $\begin{array}{l}\text { 2. REPORT TYPE } \\
\text { Interim }\end{array}$ & $\begin{array}{l}\text { 3. FeS COVERED (From - To) } \\
\text { Feb } 2010-23 \text { OCt } 2014\end{array}$ \\
\hline 4. TITLE AND SUBTITLE & 5a. CONTRACT NUMBER
\end{tabular}

MESOSCALE MODELING OF ENERGETIC MATERIALS

6. AUTHOR(S)

Michael E Nixon

Martin J. Schmidt

\section{5b. GRANT NUMBER}

5d. PROJECT NUMBER

5e. TASK NUMBER

5f. WORK UNIT NUMBER

W02Z

8. PERFORMING ORGANIZATION REPORT NUMBER

AFRL/RWML

$101 \mathrm{~W}$. Eglin BLVD

Eglin AFB, FL 32542-6810

9. SPONSORING I MONITORING AGENCY NAME(S) AND ADDRESS(ES)

AIR FORCE RESEARCH LABORATORY

MUNITIONS DIRECTORATE

$101 \mathrm{~W}$. EGLIN BLVD.

EGLIN AFB，FL 32542-6810

11. SPONSOR/MONITOR'S REPORT NUMBER

AFRL-RW-EG-2014-121

\section{DISTRIBUTION I AVAILABILITY STATEMENT}

DISTRIBUTION A. Approved for public release; distribution is unlimited; $96 \mathrm{ABW}-2012-0263$

\section{SUPPLEMENTARY NOTES}

\section{ABSTRACT}

The goal of the program is to incorporate deformation damage into material models for energetic materials and correlate the damage to changes in energetic behavior. Of primary interest is the effect on the energetic sensitivity of the material from internal damage occurring during a penetration event. Changes in the internal structure due to grain fracture and grain debonding from the matrix material may lead to both a change in the mechanical properties as well as the sensitivity to energetic behavior. This briefing represents interim progress towards these goals.

\section{SUBJECT TERMS}

Heterogeneous explosives, Mesoscale dynamics, Level set method.

\section{SECURITY CLASSIFICATION OF:}

U

\section{a. REPORT}

$\mathrm{U}$

17. LIMITATION
OF ABSTRACT
SAR

\begin{tabular}{|l|l|}
$\begin{array}{l}\text { 18. NUMBER } \\
\text { OF PAGES }\end{array}$ & $\begin{array}{l}\text { 19a. NAME OF RESPONSIBLE PERSON } \\
\text { Martin J. Schmidt }\end{array}$ \\
30 & $\begin{array}{l}\text { 19b. TELEPHONE NUMBER (include area } \\
\text { code) } \\
850-883-2686\end{array}$ \\
\hline
\end{tabular}




\title{
Mesoscale Modeling of Energetic Materials
} AFOSR Review

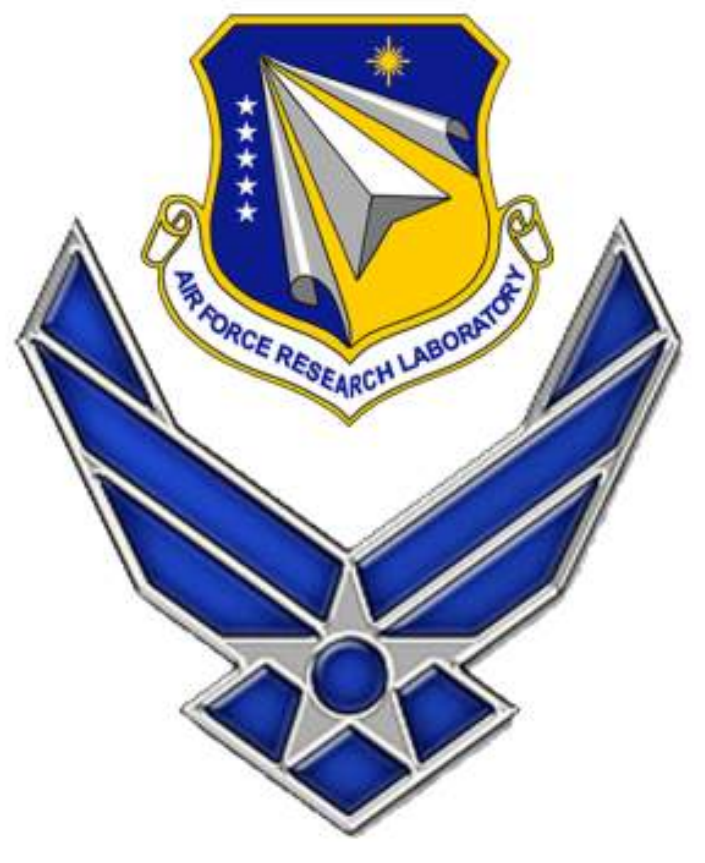

\author{
PI: Dr. Michael E Nixon \\ Co-PI: DR. Martin Schmidt \\ Sponsor: Dr. David S. Stargel \\ July 252012
}

Cleared for Public Release - 96ABW-2012-0263 


\section{Background}

- Collaborative effort within AFRL

- Computational Mechanics Branch (RWWC)

- High Explosives Research and Development Branch (RWME)

- Damage Mechanisms Branch (RWMW)

- Goal: Predict survivability of energetic payload of high speed penetrating weapons

- Approach:

- Use XCMT

- Investigate internal structure of pristine and damaged materials

- Generate representative computational meshes

- Perform meso scale simulations of composite energetic materials used in AF penetrating weapons

- Incorporate deformation damage into material models for energetic materials

- Extract data from FEM simulations of RVE's to feed thermal-reactive prediction code 


\section{Status}

- Established capability to generate computational mechanical RVE from XCMT data

- Generated experimental data for the mechanical behavior of simple explosive

- Pristine

- Damaged

- Performed simulations on mechanical RVE's

- From XCMT

- Idealized

- Developed and performed initial thermal-reactive predictions (currently under development) 


\title{
Aluminum Foam
}

Photograph

(2.75 inch $\times 2$ inch)

\author{
Slice from XCT-Scan
}
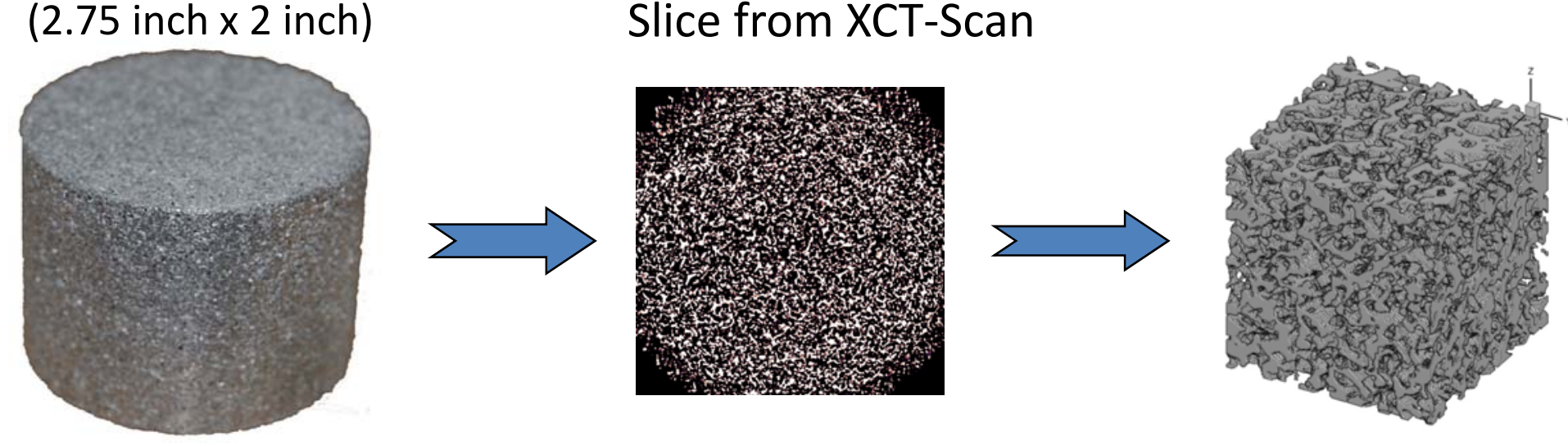

Representative Volume (10 mm x $10 \mathrm{~mm}$ x $10 \mathrm{~mm})$

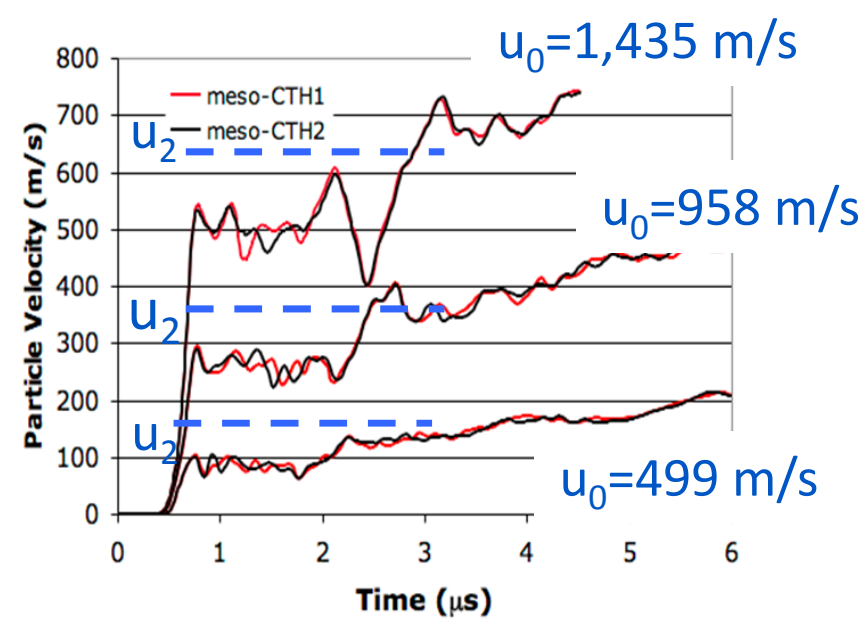

Temperature Distribution

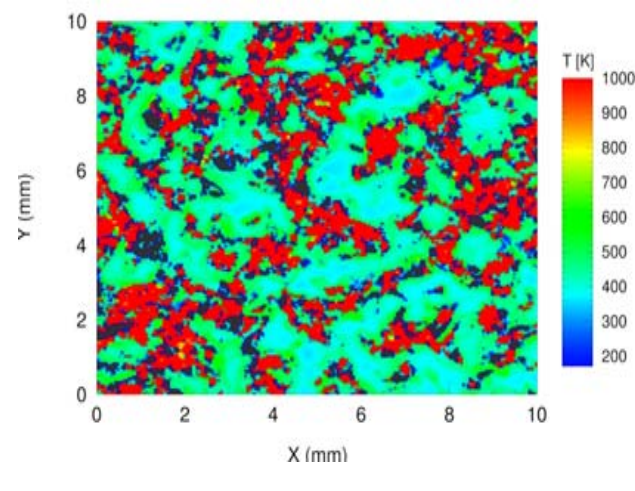

\section{Extent of Reaction} $0=$ unreacted and $1=$ reacted

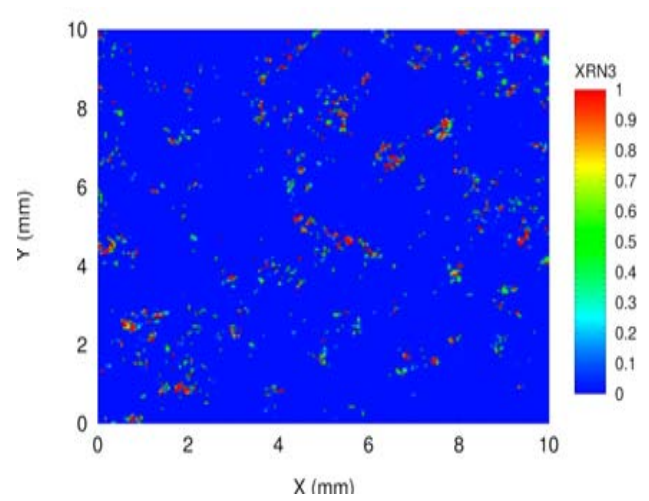

Cleared for Public Release - 96ABW-2012-0263 


\section{RVE Study}

Grayscale Histograms
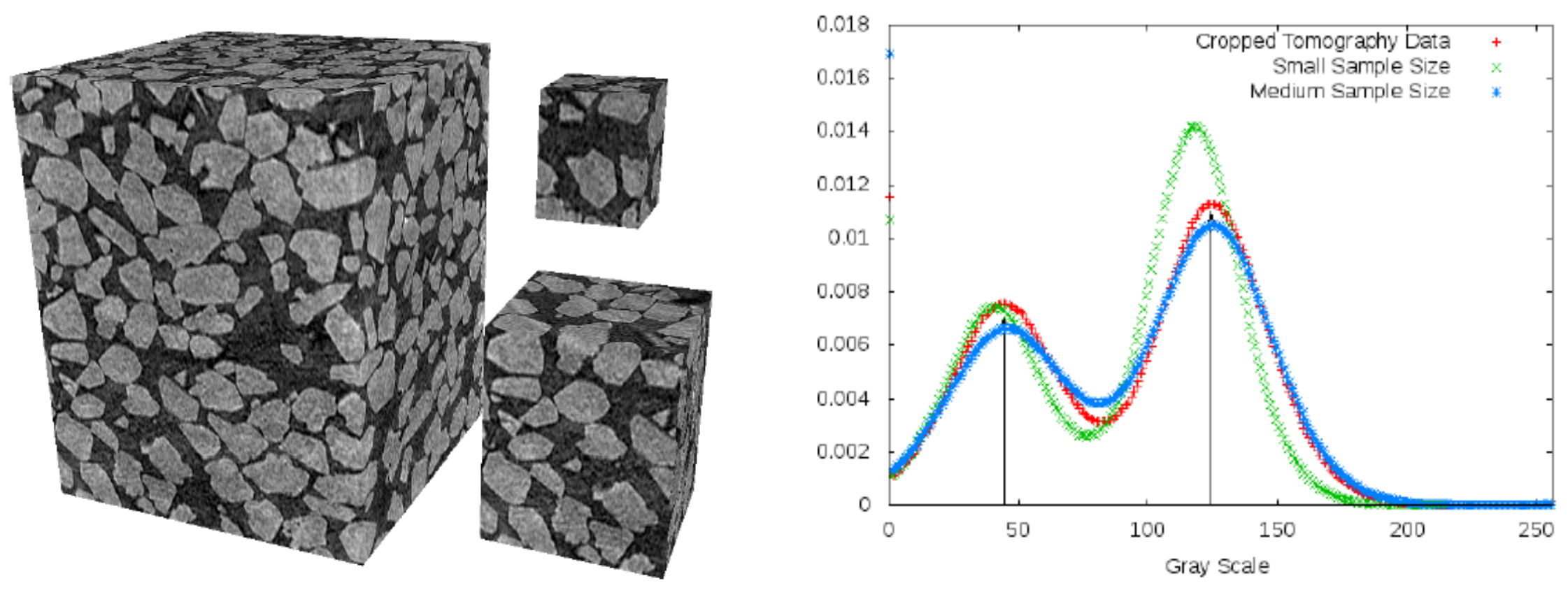

Cleared for Public Release - 96ABW-2012-0263 


\section{Pressure Loads from Systems Level Simulation}

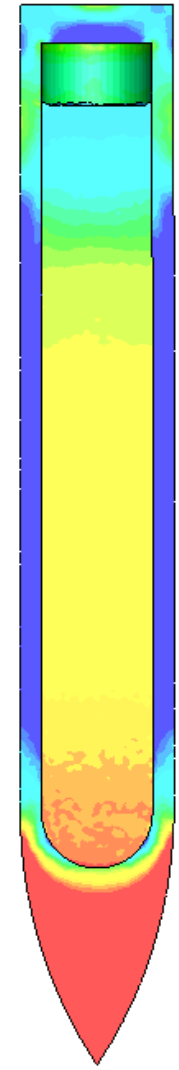

Pressure near the nose
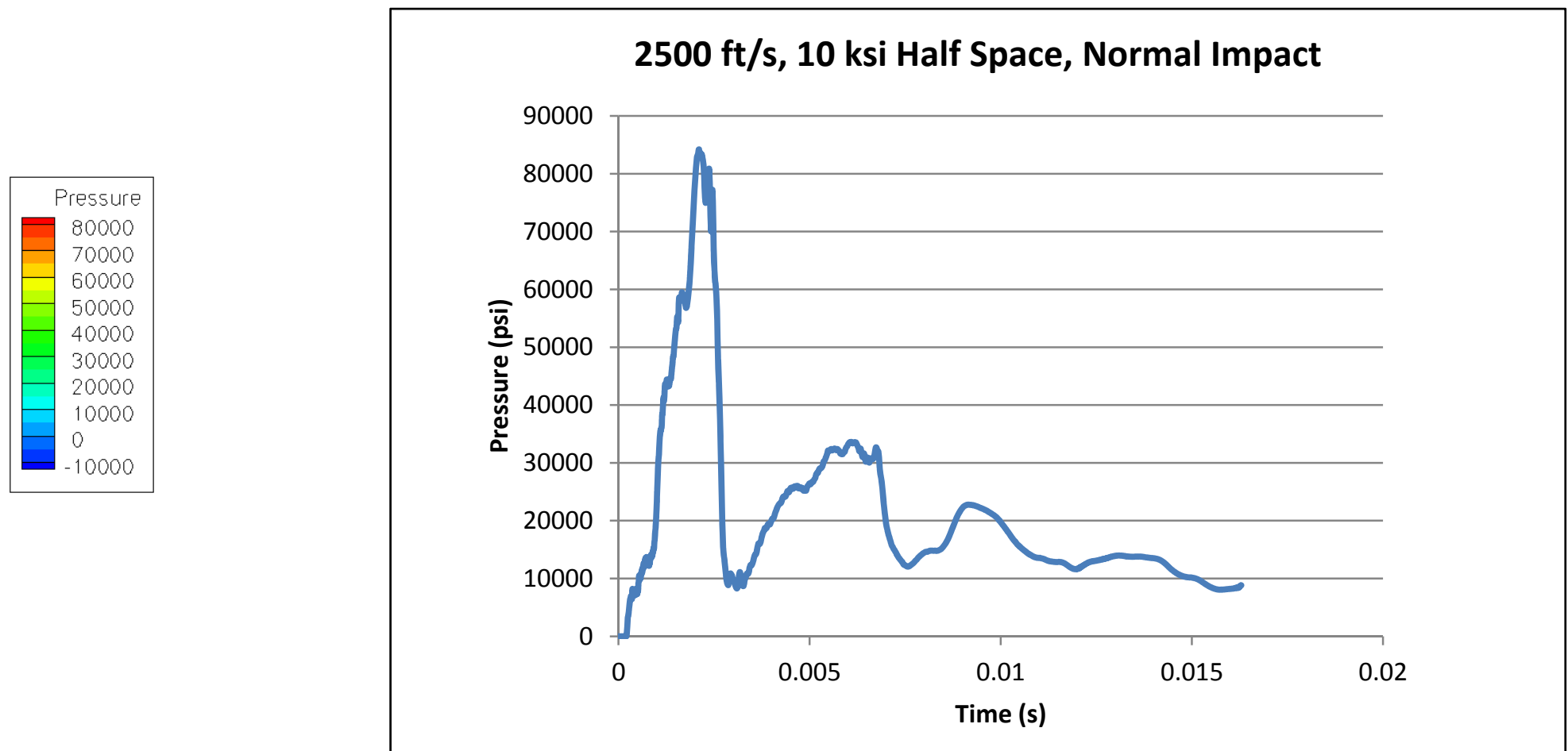

Contours of pressure shown at $0.002 \mathrm{~s}$

Cleared for Public Release - 96ABW-2012-0263 


\section{RVE from XCMT}

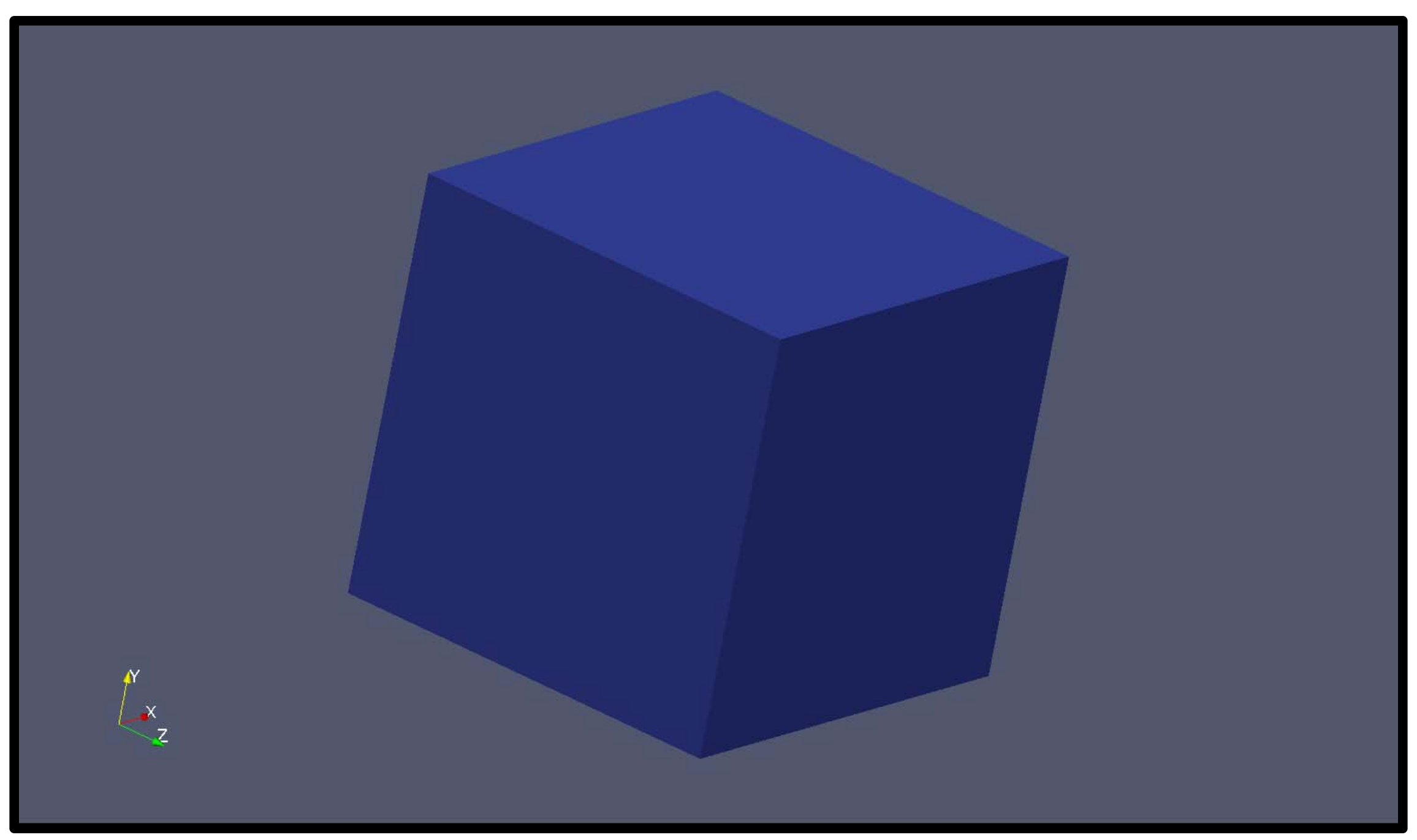

Cleared for Public Release - 96ABW-2012-0263 


\section{Characterization Data of Composite}

Specimen 1 to 5

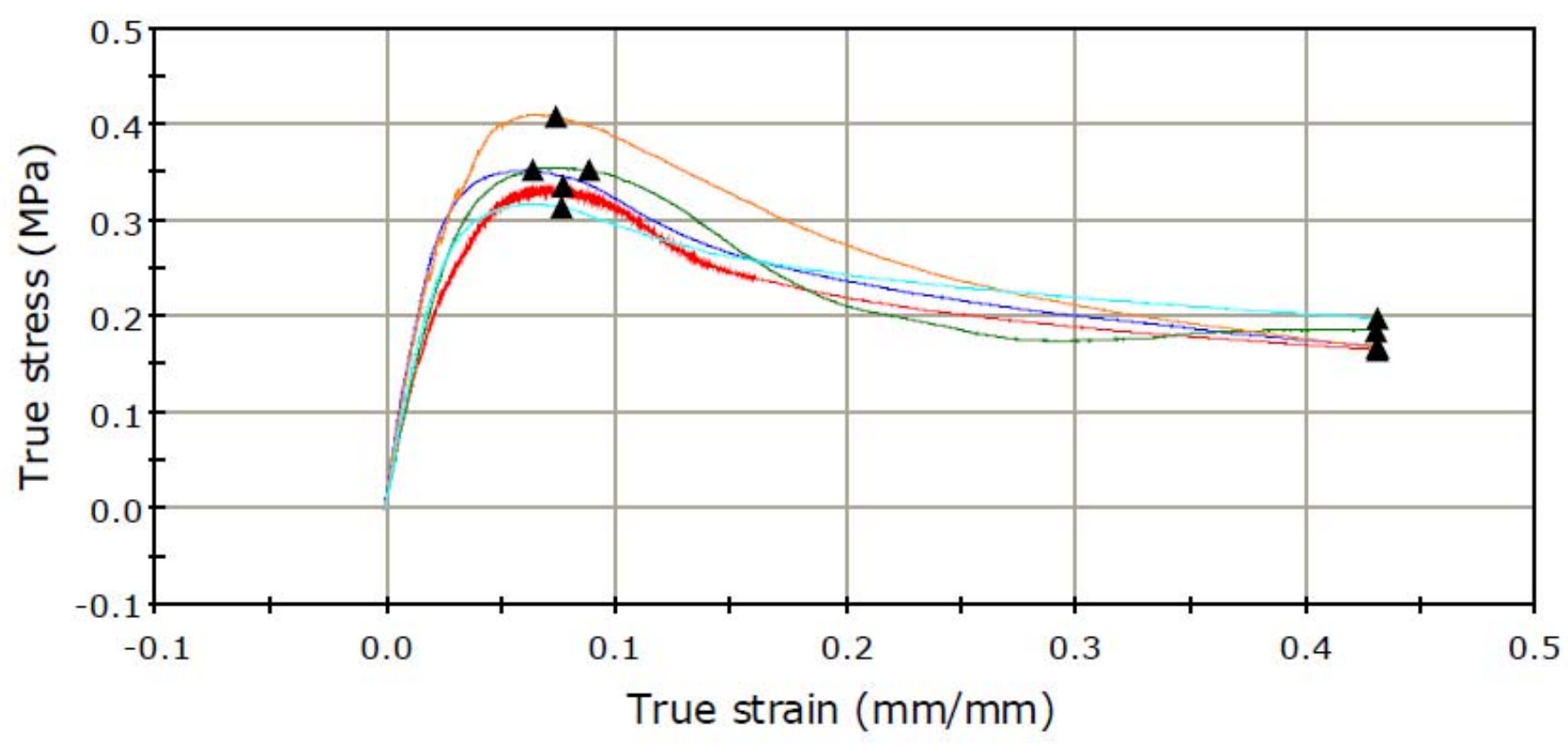

\begin{tabular}{|l}
\hline Specimen \# \\
\hline$\quad 1$ \\
\hline \\
2 \\
\\
$\square$ \\
4 \\
5
\end{tabular}

Compression Tests at $0.24 \mathrm{~mm} / \mathrm{min}$

Cleared for Public Release - 96ABW-2012-0263 


\section{Characterization Data of Composite}

Specimen 1 to 5

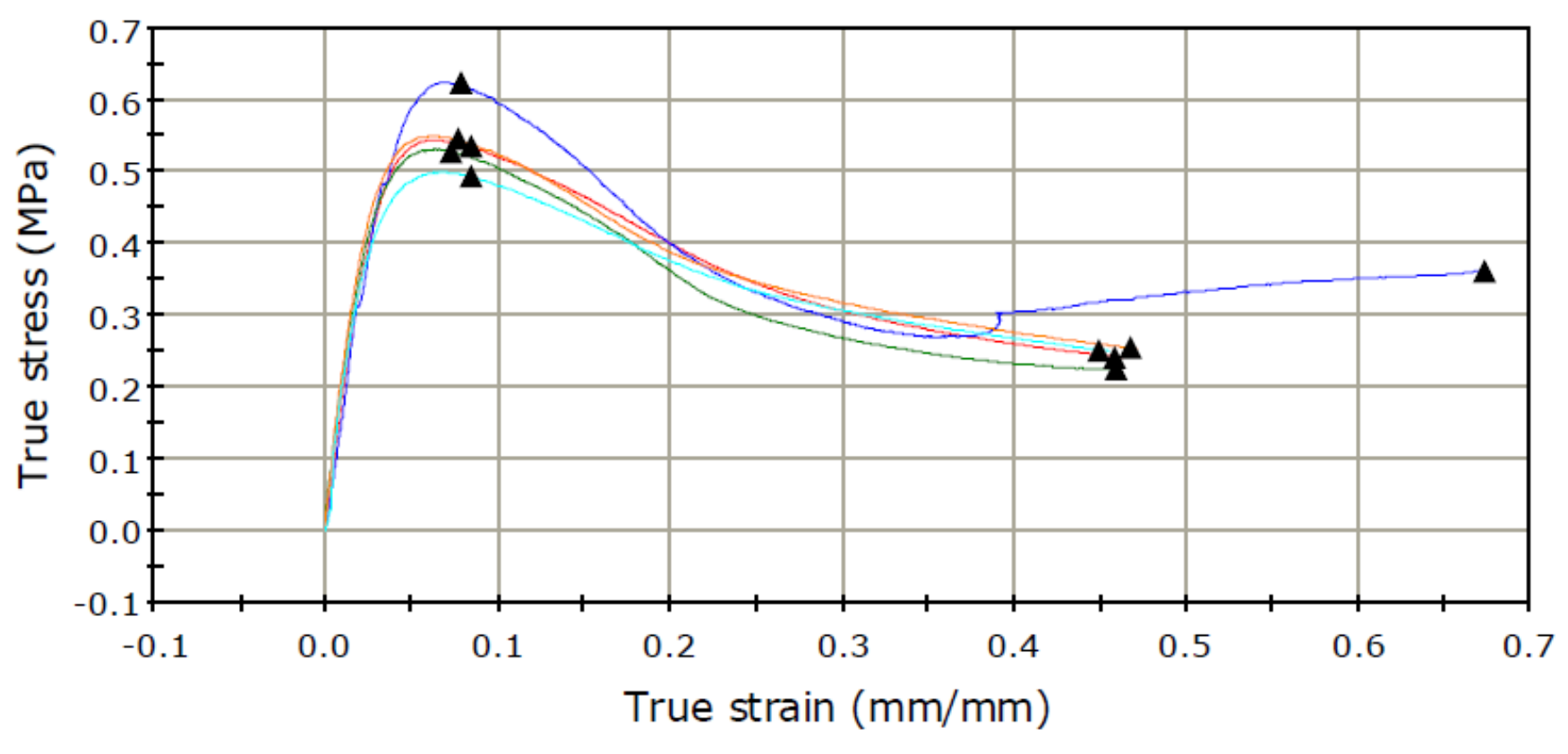

Compression Tests at $24 \mathrm{~mm} / \mathrm{min}$

Cleared for Public Release - 96ABW-2012-0263 


\section{Characterization Data of Composite}

MNX-295 DMA Sample \#1

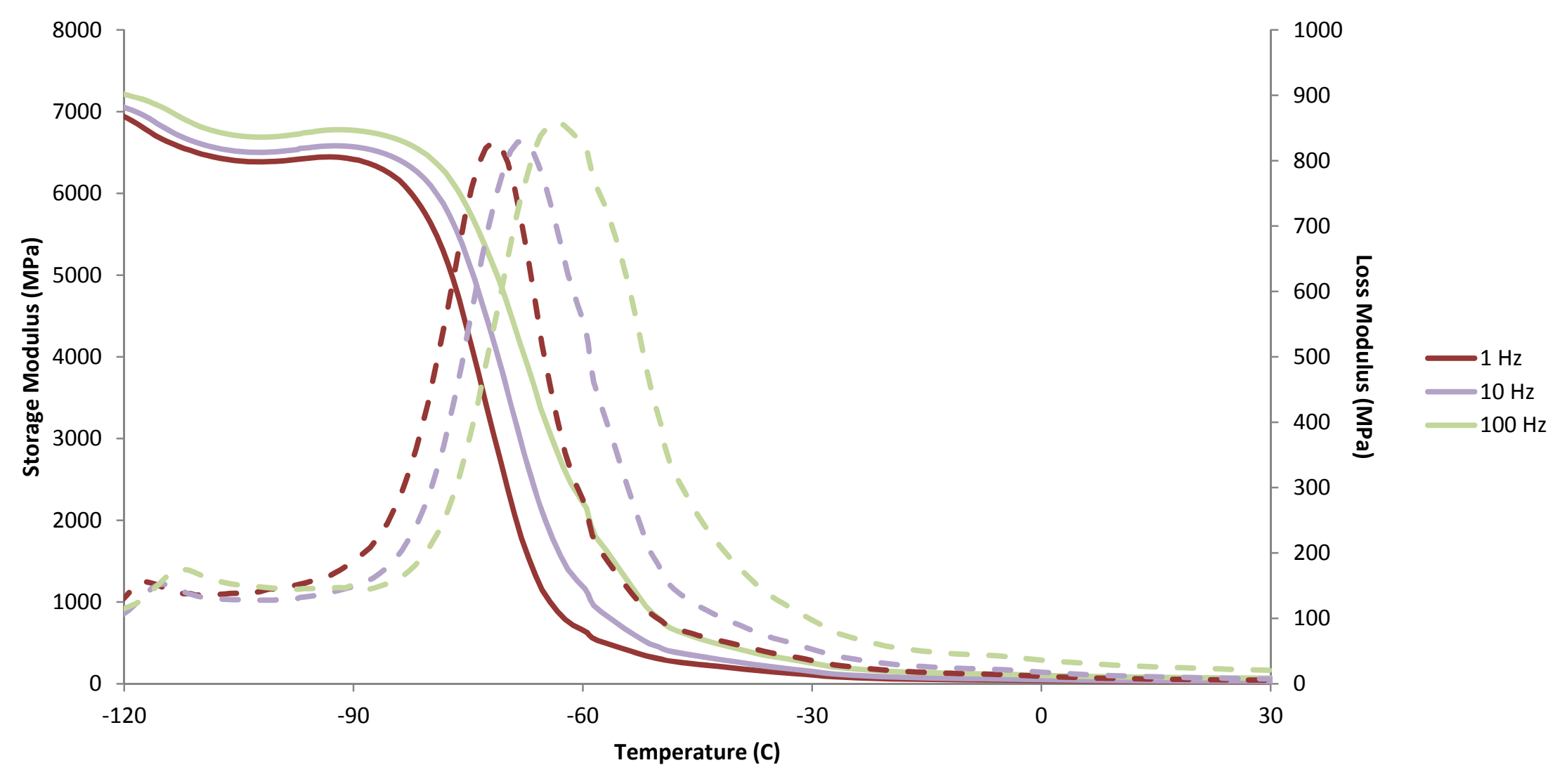

Cleared for Public Release - 96ABW-2012-0263 


\section{Thermal-reactive Model}

- We can use nearest-neighbor distributions to help quantify explosive morphology.

- We may estimate statistical distributions of the heterogeneous temperature rise that results from mechanical loading.

- These distributions can be used to initialize a thermal-reactive representative volume element (RVE), which is called a "realization".

- Many realizations can be initiated using the same statistics.

- Not all realizations will undergo complete chemical reaction, even with adiabatic RVE boundary conditions.

- We are interested in this uncertain "region", or ignition threshold. It is our goal to understand and quantify this uncertainty.

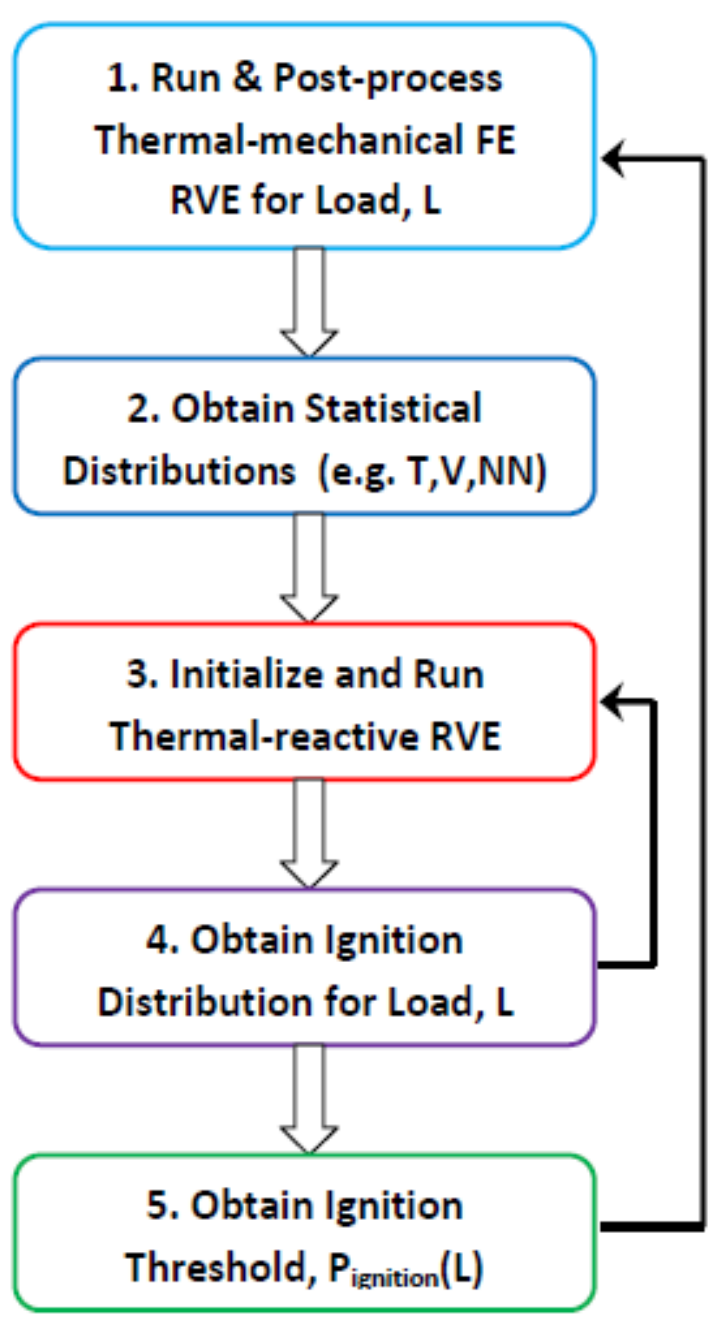

Cleared for Public Release - 96ABW-2012-0263 


\section{Main Steps: Processing and Post-processing}

Step \#1: Run and post-process the finite element (FE) RVE

a. Specify a loading condition and run the FE simulation.

b. Post process the following for each crystal:

i. centroids, $X_{i}$

ii. size or volume, $v_{i}$

iii. maximum temperature, $T_{\max , i}$

iv. average temperature, $\mathrm{T}_{\mathrm{avg}, \mathrm{i}}$

Step \#2: Obtain statistics (Gaussian mean $\mu$ and std. deviation $\sigma$ )

a. Use the cutoff temperature, $T_{c}$, to classify each $T_{\text {max, }}$ as either a H.S. (hot spot) or a C.S. (cold spot).

b. For H.S. $-\mathrm{T}_{\text {max,i }}, \mathrm{T}_{\mathrm{avg}, \mathrm{i}}, \mathrm{V}_{\mathrm{hs}, \mathrm{i}}$ and $\mathrm{NN}_{\mathrm{hs}}$ (nearest neighbor), find $\mu$ and $\sigma$.

c. For C.S. $-\mathrm{T}_{\mathrm{avg}, \mathrm{i}}, \mathrm{V}_{\mathrm{cs}, \mathrm{i}}$, and $\mathrm{NN}_{\mathrm{cs}}$, find $\mu$ and $\sigma$.

d. For H.S. $-\mathrm{NN}_{\mathrm{tmax}}$, find find $\mu$ and $\sigma$ for 3 bins using all H.S. $\mathrm{T}_{\max }$ values. 


\section{Main Steps: Processing and Post-processing}

Step \#3: Initialize and run a realization of a thermal-reactive RVE

a. For H.S., randomly initialize centroid values, $x_{h s, i}$ with $\mathrm{V}_{\mathrm{i}}=\mathrm{V}_{\mathrm{hs}}(\mu, \sigma)$.

b. For H.S., synthetically anneal $\mathrm{X}_{\mathrm{hs}, \mathrm{i}}$ to fit desired $\mathrm{NN}_{\mathrm{hs}}$ distribution.

c. For H.S., randomly assign hot spot $T_{\text {max,i }}$.

d. For H.S., anneal the 3 temperature nearest neighbor distributions using $\mathrm{NN}_{\text {tmax }}$ values.

e. For C.S., randomly initialize centroid values, $\mathrm{X}_{c s, i}$ with $\mathrm{V}_{\mathrm{i}}=\mathrm{V}_{\mathrm{cs}}(\mu, \sigma)$.

f. For C.S., synthetically anneal $\mathrm{X}_{\mathrm{cs}, \mathrm{i}}$ to fit desired $\mathrm{NN}_{\mathrm{cs}}$ distribution.

g. Run the thermal-reactive RVE simulation.

Step \#4: Obtain ignition distribution for a given load, $\mathrm{L}$

a. Repeat Step \#3 many times and record ignition results (either yes or no ignition).

b. Calculate the ignition probability based on multiple realizations for a single load, L.

Step \#5: Obtain ignition threshold as a function of load, L

a. Repeat Steps \#1-4.

b. Calculate the ignition threshold as $P_{1}(L)$ as a function of the load, $L$, where $P_{1}$ is the probability of ignition that is obtained from the ignition probability in Step \#4.

Cleared for Public Release - 96ABW-2012-0263 


\section{Synthetic Annealing}

- Assume that the nearest neighbor, NN1, distribution is Gaussian

$P\left[d_{k} \|\left(d_{i}-\delta d / 2\right)<d_{k} \leq\left(d_{i}+\delta d / 2\right)\right]=a_{N N} \exp \left\{-\frac{1}{2}\left(\frac{d_{i}+\mu}{\sigma}\right)^{2}\right\}$

- for $\mathrm{i}=1, \ldots . N_{d}$, where $N_{d}=$ number of bins to discretize NN1

- $\delta d=$ width of the bins

- $\mu=$ mean distance

- $\sigma=$ standard deviation of the distance

- $a_{N N}=$ scaling parameter so that sum of $d_{i}$ probabilities sum to unity

$$
a_{N N} \cdot \sum_{i=1}^{N_{d}} P\left(d_{i}\right)=1
$$

Cleared for Public Release - 96ABW-2012-0263 


\section{Synthetic Annealing}

- We let $P\left(d_{i}\right)_{\text {syn }}$ denote the synthetic probability obtained from the annealed configuration and $P\left(d_{i}\right)_{a c t}$ denote the actual or experimental distribution.

- The objective function to be minimized is

$$
e_{N N}=\sqrt{\sum_{i=1}^{N_{d}}\left(P\left(d_{i}\right)_{s y n}-P\left(d_{i}\right)_{a c t}\right)^{2}}
$$

- Procedure:

a) Randomly assign crystal centroids to locations

b) A subset of the centroids are randomly perturbed in the $x, y$, and $z$ directions. 


\section{Synthetic Annealing}

- Procedure (cont.):

c) The objective function is evaluated again to give a new $e_{N N}$.

d) If the new value of $e_{N N}$ is smaller than the previous value, then the new configuration is kept. If not, then the probability that the configuration will be kept is given by,

$P=\exp \left\{-d e_{N N} / T_{v}\right\}$

$T_{v}=$ virtual temperature (can be a function of number of attempts)

e) Steps $b$-d are repeated until either i) the maximum number of attempts has been reached, or ii) the number of temperature $\left(T_{v}\right)$ decrements has been reached. 


\section{Example: Step \#3}

- The random centroid distribution is shown below.

- Hot spots (hs, red) and cold spots (cs, blue).

$\mathrm{N}_{\mathrm{hs}}=4$ to 12 (varies linearly with load)

$\mathrm{N}_{\text {total }}=30$ crystals

$\mathrm{N}_{\mathrm{cs}}=\mathrm{N}_{\text {total }}-\mathrm{N}_{\mathrm{hs}}$

$\mathrm{Lx}=\mathrm{Ly}=\mathrm{Lz}=15$ microns

$\mu_{(\mathrm{D}, \mathrm{hs})}=\mu_{(\mathrm{D}, \mathrm{cs})}=2$ microns

$\sigma_{(\mathrm{D}, \mathrm{hs})}=\sigma_{(\mathrm{D}, \mathrm{cs})}=1$ microns

Min diameter $=0.5$ micron ( $h s$ and $c s$ )

$\mu_{(\mathrm{NN} 1, \mathrm{hs})}=\left(4.5-\mathrm{N}_{\mathrm{hs}} / 20\right) * 1 \mathrm{e}-6$ microns

$\mu_{(\mathrm{NN} 1, \mathrm{cs})}=\left(3.0-\mathrm{N}_{\mathrm{cs}} / 20\right) * 1 \mathrm{e}-6$ microns

$\sigma_{(\mathrm{NN} 1, \mathrm{hs})}=\sigma_{(\mathrm{NN} 1, \mathrm{cs})}=1$ microns

$\mathrm{nx}=\mathrm{ny}=\mathrm{nz}=31$

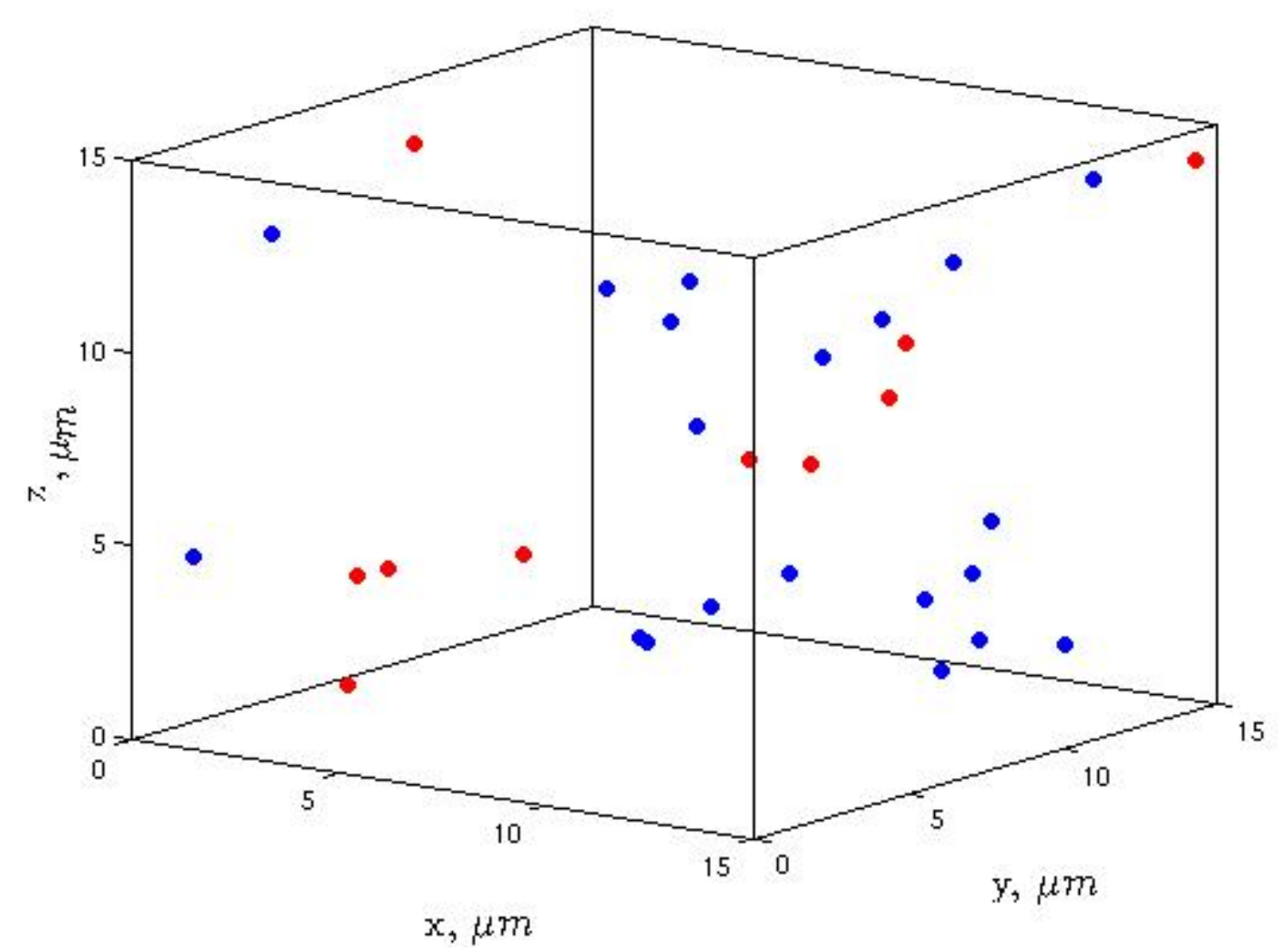

Cleared for Public Release - 96ABW-2012-0263 


\section{Example: Step \#3}

Hot spot centroid annealing - nearest neighbor distribution(NN1)

$\mathrm{N}_{\text {attempt }}=300, \mathrm{D}_{\text {move }}=2 * \mathrm{dx}, \mathrm{T}_{\text {virtual }}=80, \varphi_{\text {move }}=0.20$

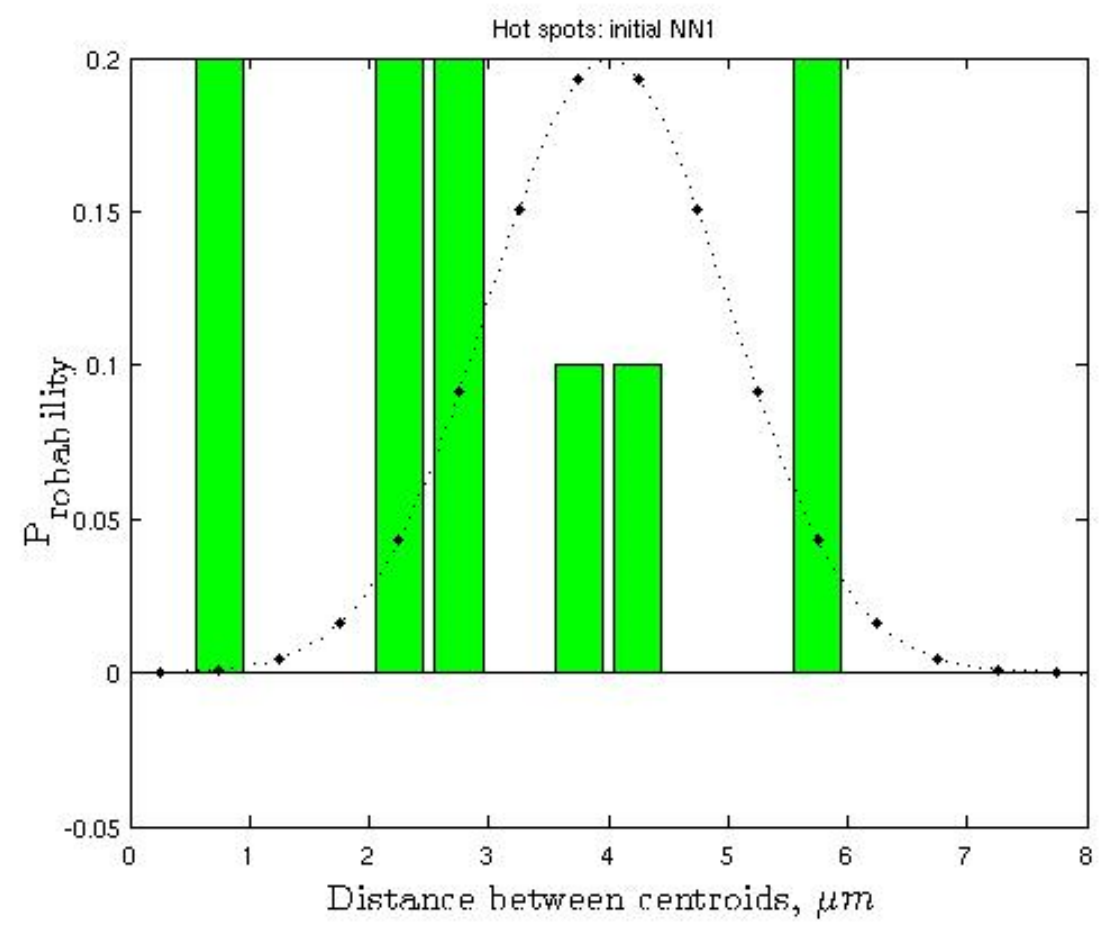

ENN1 $($ random $)=0.4151$

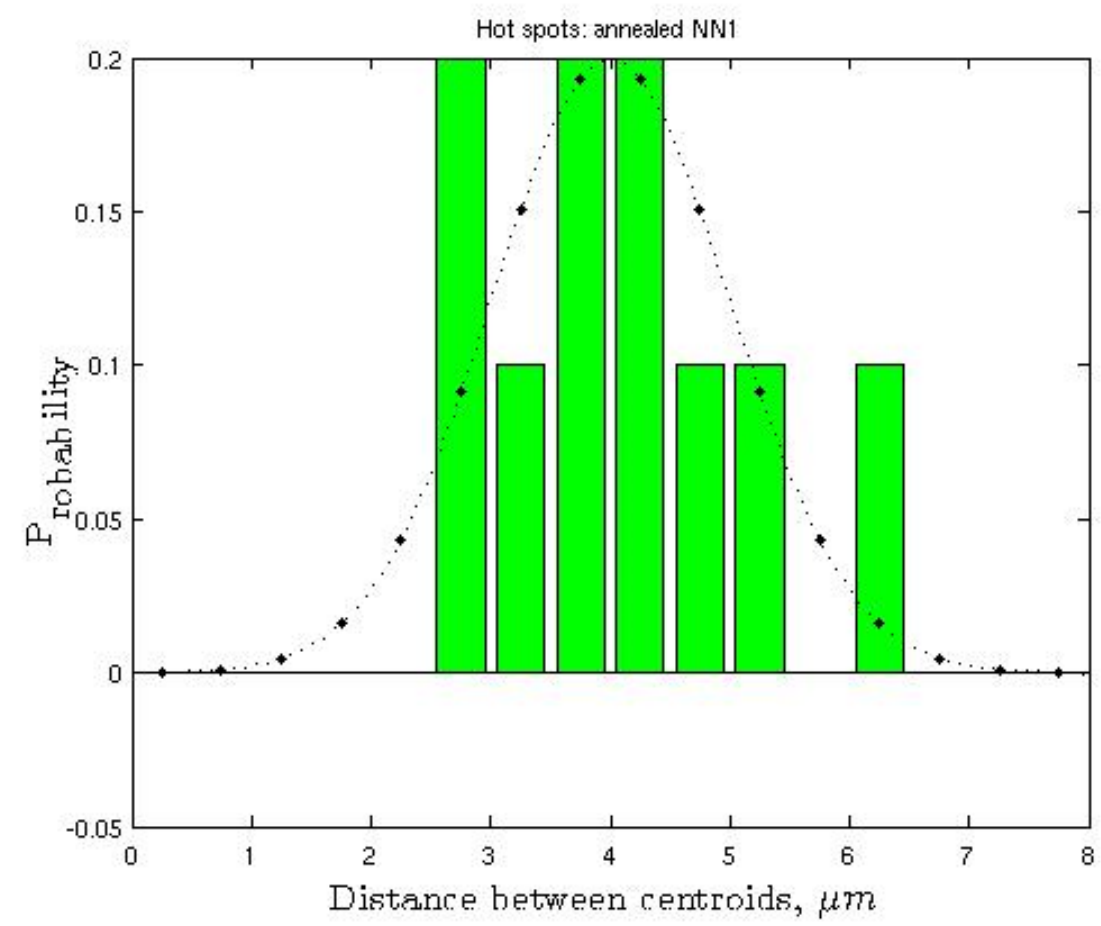

ENN1 (annealed) $=0.1679$

Cleared for Public Release - 96ABW-2012-0263 


\section{Example: Step \#3}

Non-hot spot centroid annealing - nearest neighbor distribution(NN1)

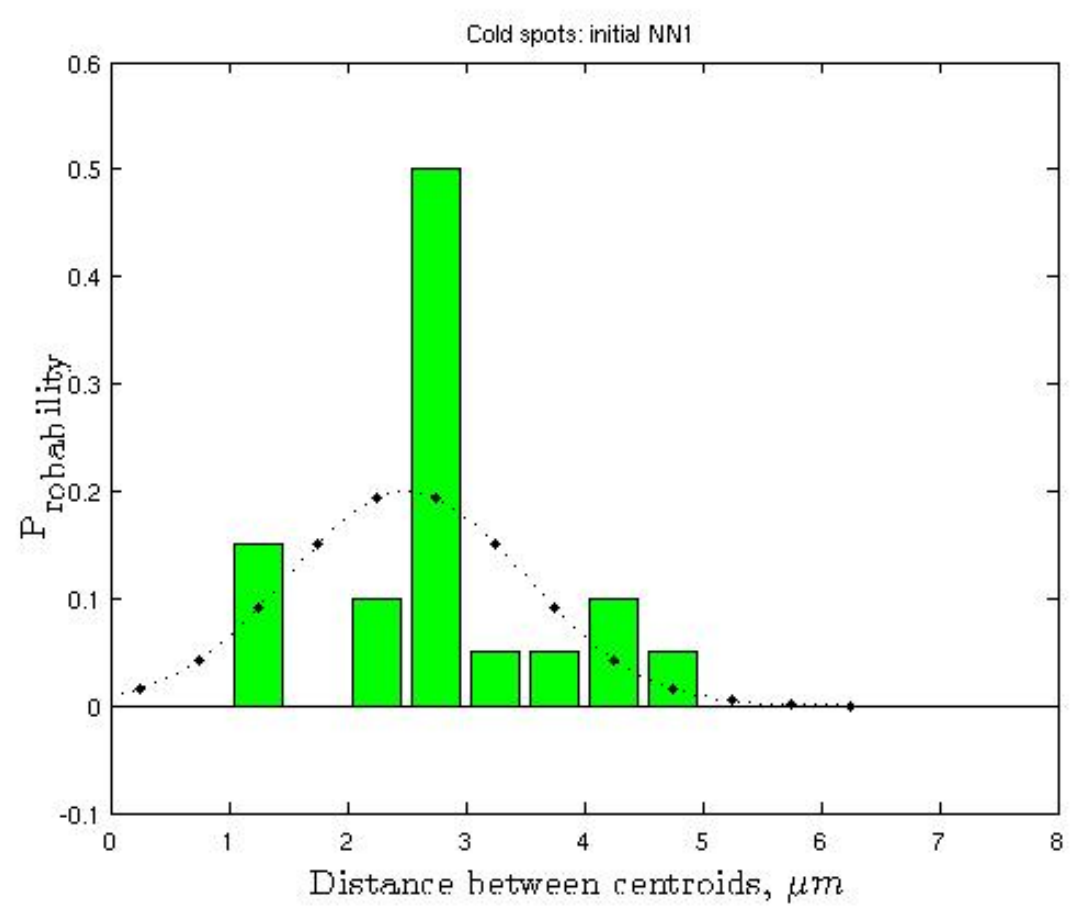

ENN1 $($ random $)=0.3837$

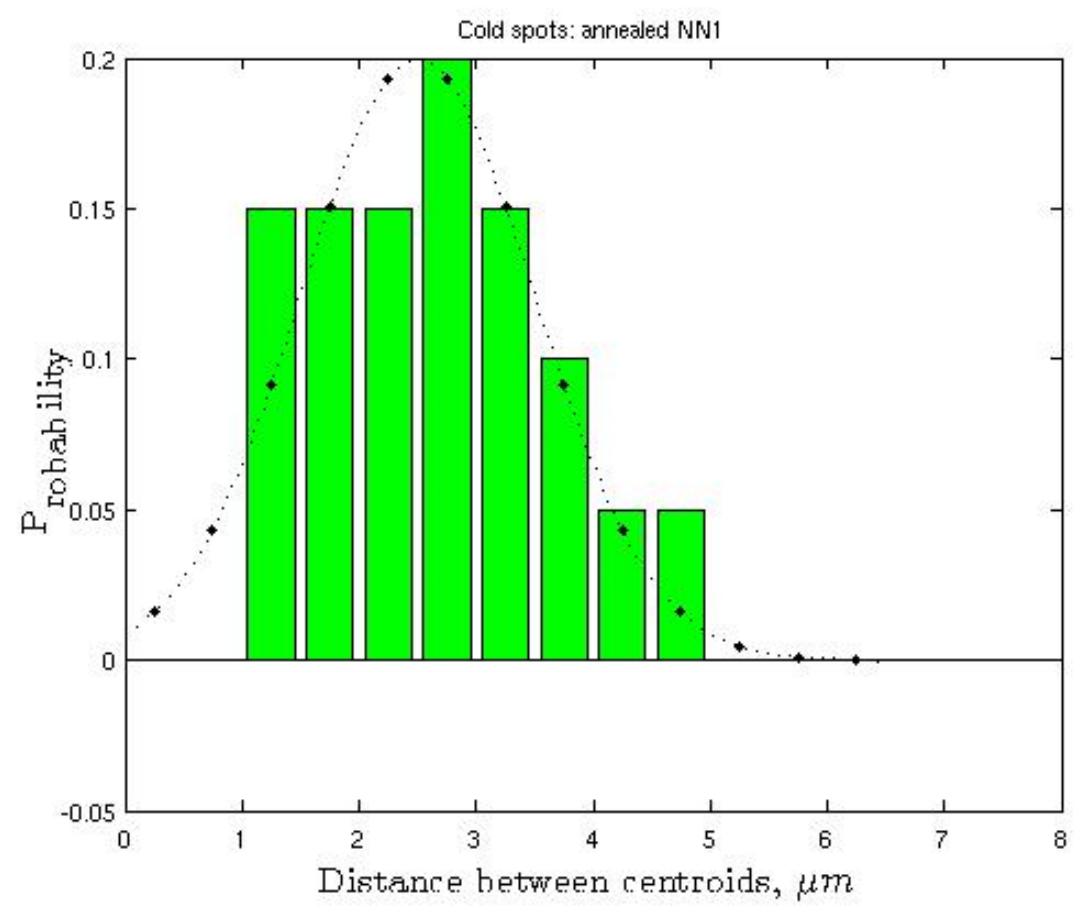

ENN1 (annealed) $=0.0939$

Cleared for Public Release - 96ABW-2012-0263 


\section{Example: Step \#3}

Demonstration assumptions for this example:

- All grains have the same volume.

- Initial temperature, within each grain, is equal to the bulk temperature of the RVE.

- The material properties $\mathrm{Cp}$, rho, kc, and dHrxn are all constant.

- The hot spot maximum temperature distribution is constant.

- Loading is simulated by linearly varying the bulk temperature and the number of hot spots.

- There is no correlations between crystal temperature and the NN1 distribution.

- The RVE is adiabatic, and it has symmetric boundary conditions. 


\section{Example: Step \#3}

- (Right) Temperature contour on one face of the RVE cube at 300 microseconds.

- Periodic boundary conditions.

Run time $=300$ microseconds

$\mu_{(\mathrm{T}, \mathrm{hs})}(\mathrm{avg})=800 \mathrm{~K}$

$\mu_{(\text {, }, \text { bulk })}($ avg $)=522$ to $625 \mathrm{~K}$

$\sigma_{(\mathrm{T}, \mathrm{hs})}(\operatorname{avg})=100 \mathrm{~K}$

$\sigma_{(T, c s)}($ avg $)=100 \mathrm{~K}$

$\mathrm{CFL}=0.6$

$\mathrm{kc}$ (conductivity) $=0.2 \mathrm{~W} / \mathrm{m} * \mathrm{~K}$

$\mathrm{Cp}=1466 \mathrm{~J} / \mathrm{kg}^{* \mathrm{~K}}$

$\mathrm{Rho}=1180 \mathrm{~kg} / \mathrm{m}^{\wedge} 3$

$\mathrm{dHrxn}$ (heat of reaction) $=2.0 \mathrm{e} 9 \mathrm{~J} / \mathrm{m}^{\wedge} 3$

$\mathrm{T}_{\text {critical }}=700 \mathrm{~K}$ (crystal ignition criterion

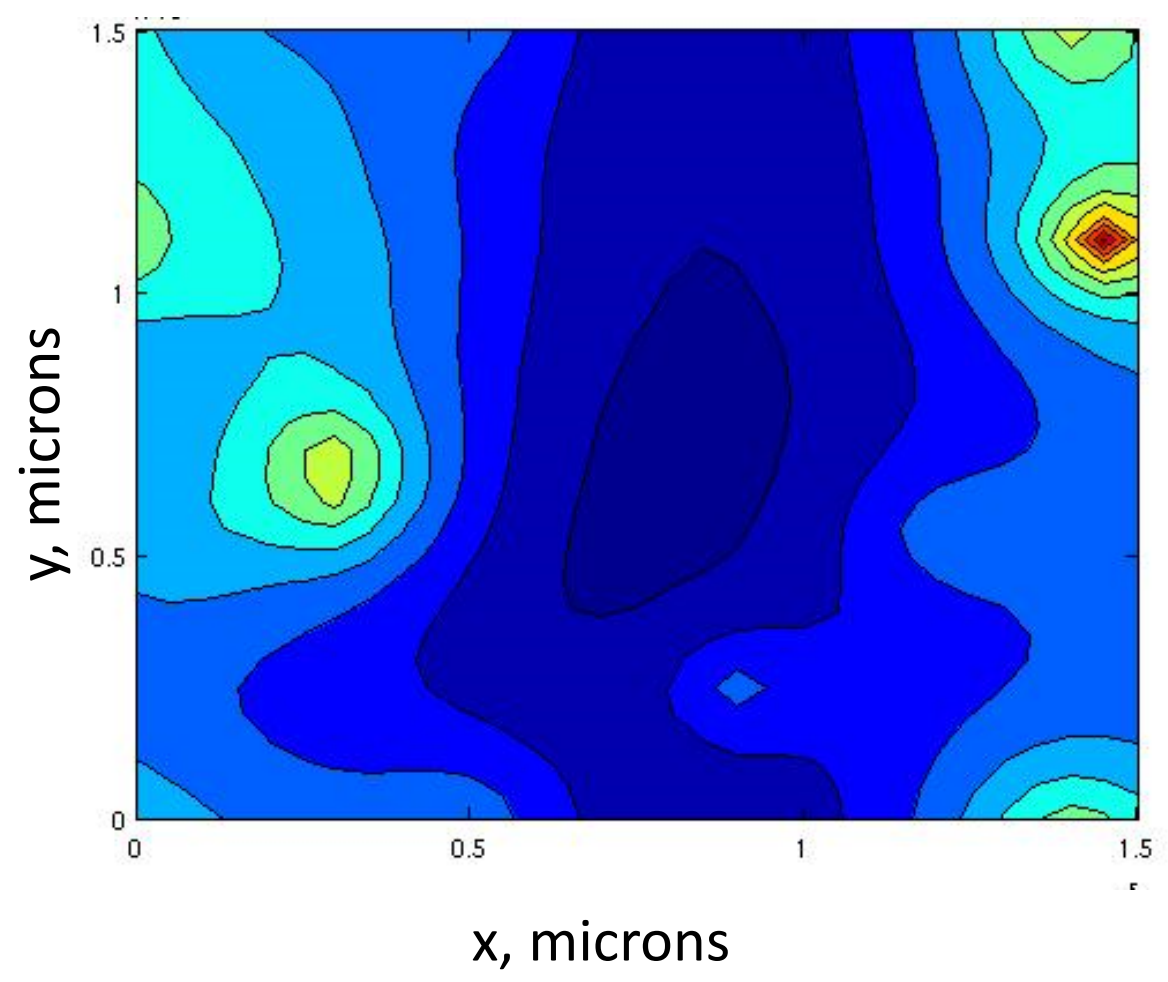

Cleared for Public Release - 96ABW-2012-0263 


\section{Example: Steps \#4-5}

- A single loading condition shows the average crystal temperature, not the bulk RVE temperature.

- 20 realizations for each loading condition.

- $\quad$ Threshold is approximately 530 to $580 \mathrm{~K}$ (50 degree range)
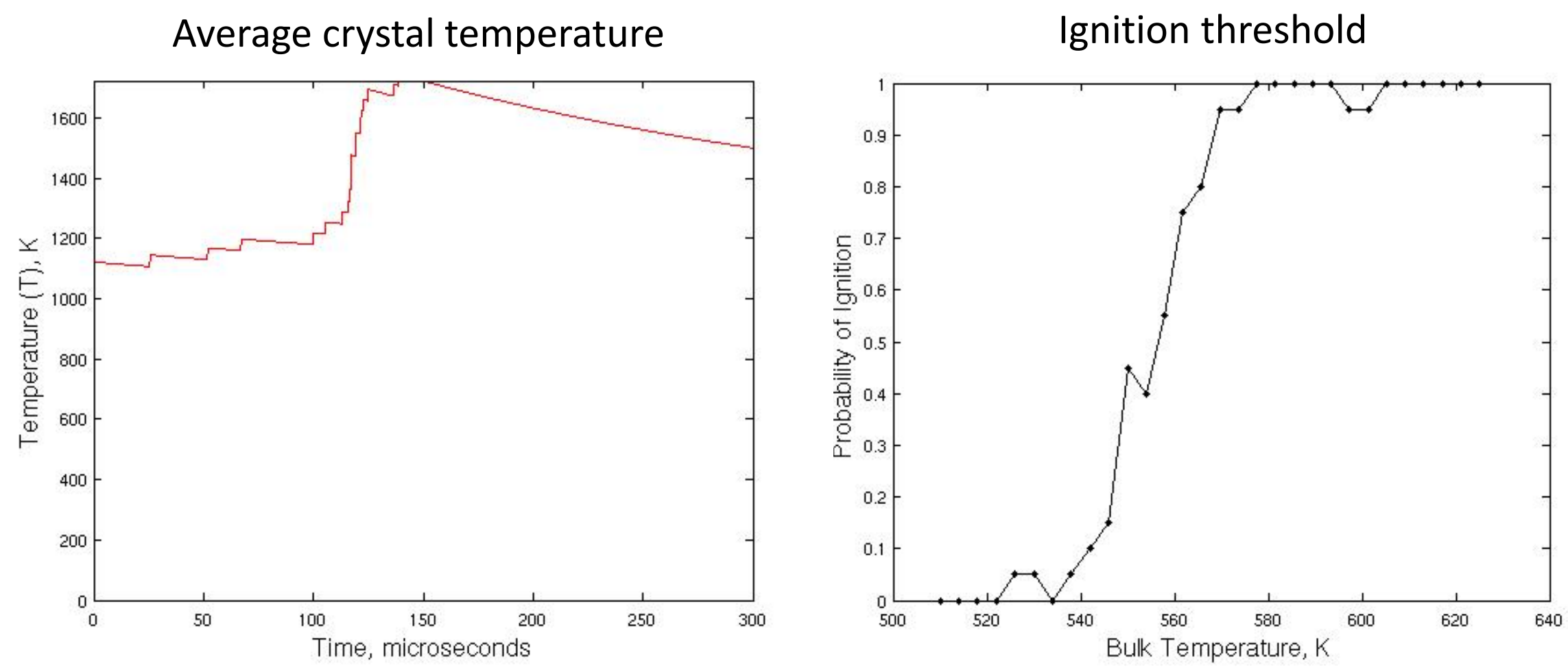

Cleared for Public Release - 96ABW-2012-0263 


\section{Summary}

- Can generate meshes from XCMT

- Have experimental data of mock and explosive composite

- Have carried out simulations on mechanical RVE's from XCMT and idealized

- Developed and demonstrated thermal ignition predictive approach 


\section{Future Work}

- Develop approaches for extracting data from FEM to feed thermal ignition code

- Improve temperature computation approach in FEM

- Implement better thermal-reactive modeling

- Quantify the range of validity using experiments 


\section{Related Efforts}

- SBIR's

- Phase 2 PENETRATION SURVIVABLE ADVANCED ENERGETIC

- Symmetrix

- Streamline

- Illinois RocStar

- STTR's

- Phase I with Multiscale Design

- Topic on NDE for low density gradient materials

- Los Alamos NL

- Should soon have a signed Project Agreement with Germany

- Udaykumar of University of lowa 
Cleared for Public Release - 96ABW-2012-0263 
DISTRIBUTION LIST

AFRL-RW-EG-TR-2014-121

Defense Technical Information Center

1 Electronic Copy (1 File \& 1 Format)

Attn: Acquisition (OCA)

8725 John J. Kingman Road, Ste 0944

Ft Belvoir, VA 22060-6218

\section{EGLIN AFB OFFICES:}

AFRL/RWOC (STINFO Office) - 1 Hard (Color) Copy

Distribution A, Approved for public release; distribution is unlimited; 